\title{
A field-based technique for sediment incubation experiments
}

\author{
Diane M. ORIHEL, ${ }^{*}$ and Rebecca C. ROONEY \\ Department of Biological Sciences, University of Alberta, 11455 Saskatchewan Drive, Edmonton, Alberta T6G 2E9, Canada \\ *Corresponding author: orihel@ualberta.ca
}

\begin{abstract}
Sediment incubation experiments have been a cornerstone in limnology for improving our understanding of sediment processes in aquatic ecosystems. Experiments are usually performed in the laboratory, which has several limitations, including: additional handling that may disturb the integrity of the sediments, the financial expense of purchasing and maintaining growth chambers and anaerobic gloveboxes, and the inability to exactly recreate the ambient environmental conditions experienced by sediments in natural ecosystems. Furthermore, laboratory-based techniques are simply not possible with flocculent sediments from eutrophic ecosystems that are highly prone to separation following changes in pressure. Here, we describe a field-based technique for incubating sediment cores that is simple, versatile, and inexpensive. Our in situ incubation technique is highly effective for exposing sediments to natural temperature, pressure, and light regimes, and easily maintaining sediments under anaerobic conditions.
\end{abstract}

Key words: benthic lander; in situ technique; lake sediments.

Received: July 2011. Accepted: September 2011.

\section{INTRODUCTION}

Sediment incubation experiments are widely used in limnology. For example, this approach has been used to study the metabolism of microbial communities (e.g., Schwarz et al. 2008), the sediment-water exchange of nutrients (e.g., Nowlin et al. 2005), the transformation rates of contaminants (e.g., Gilmour and Riedel 1995), and the effectiveness of potential sediment remediation techniques (e.g., Burley et al. 2001). Sediment incubations are typically carried out in the laboratory - an approach that has a number of limitations. For instance, sediment cores are often disturbed during transport between the field and the laboratory, which could potentially confound the results of the experiment. Laboratory-based experiments also require, at a minimum, a growth chamber to control temperature and light, and/or an anaerobic glove box in the case of anoxic incubations. Despite the time and money spent trying to simulate field conditions, it is not possible to recreate them exactly, which makes extrapolating results from laboratory experiments to natural ecosystems tenuous. Finally, laboratory-based incubation experiments are simply not possible with highly flocculent sediments from eutrophic lakes, as we explain below. In this paper, we describe a field technique for sediment core incubations that circumvents these and other issues.

\section{STATEMENT OF PROBLEM}

We sought to conduct incubation experiments with sediment cores collected from Lake 227 at the Experimental Lakes Area (ELA), Ontario, Canada. Lake 227 is small boreal lake (surface area of 5 ha; maximum depth of 10 $\mathrm{m})$ that has been made eutrophic by over 40 years of experimental nutrient additions (Schindler et al. 2008). The lake is strongly stratified and the hypolimnion is anoxic for most of the year (Schindler et al. 1987). The surface sediments are rich in organic matter $(>50 \%)$ and have a high water content (>95\%) (Schindler et al. 1987). For our incubation experiments, we collected hypolimnetic sediments in acrylic $60-\mathrm{cm}$ tubes using a KajakBrinkhurst gravity-driven sediment corer from water depths of 6 to $10 \mathrm{~m}$.

We encountered major problems attempting to perform laboratory-based incubation experiments with sediments from Lake 227. The sediment cores frequently "separated" soon after collection, during transport from the field site back to the laboratory, or during the incubation period in the laboratory. Gas bubbles, presumably consisting of methane, were observed to form approximately $6-10 \mathrm{~cm}$ below the sediment water interface. These bubbles cleaved the surface sediments from the deeper sediments, causing the surface sediment layer to float to the top of the water column. The failure to maintain intact sediment cores from Lake 227 repeatedly ruined our experiments. Similar problems have been encountered with cores from other lakes at ELA (D.W. Schindler, University of Alberta, personal communication), particularly meromictic lakes where methane concentrations as high as 11,000 $\mu$ moles $\mathrm{L}^{-1}$ have been recorded in waters below the chemocline (Campbell 1976).

We initially attempted to overcome the "sediment separation" problem by ensuring the cores were kept at 


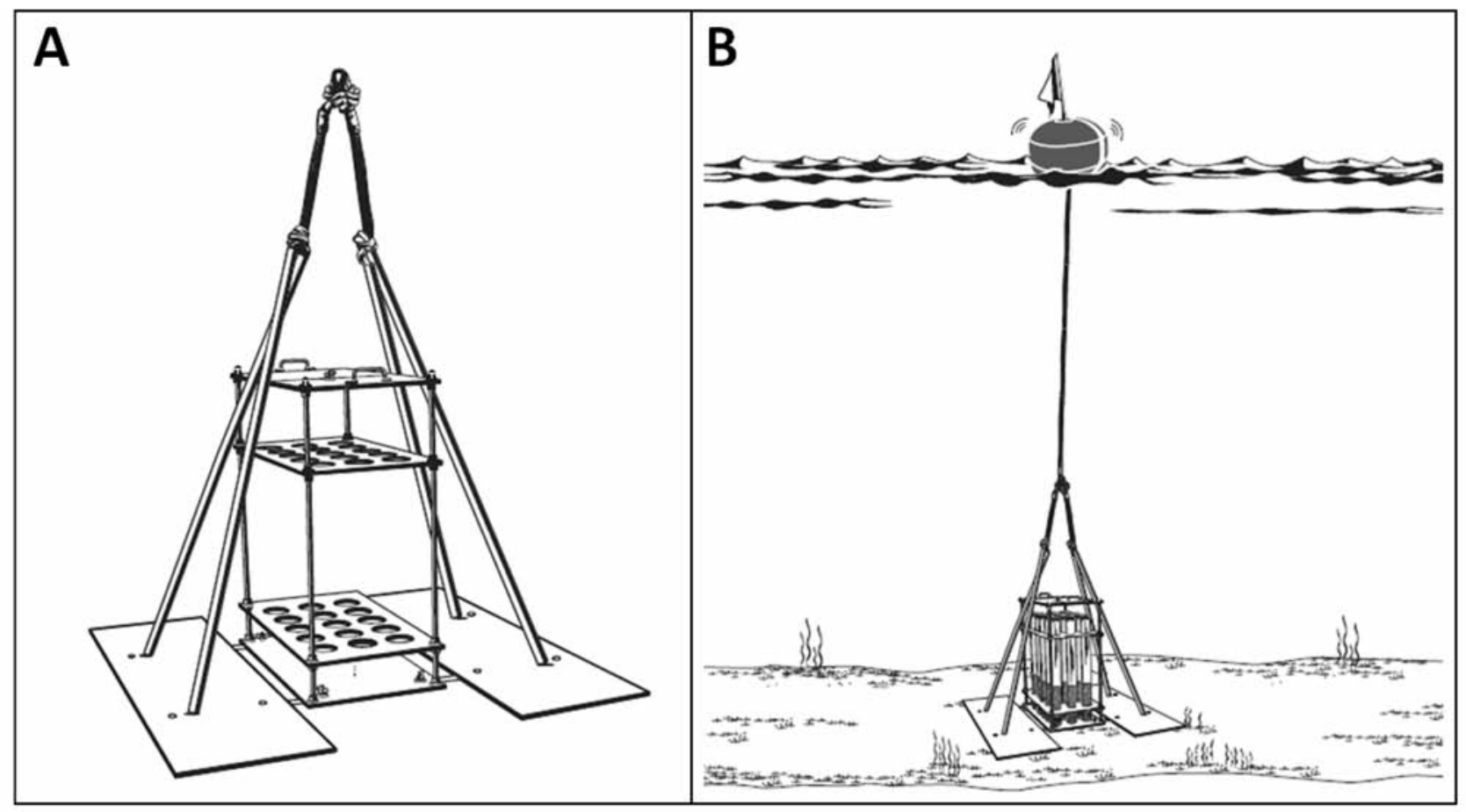

Fig. 1. The Sediment Core Lander in detail (A) and at the bottom of the lake (B).

the ambient temperature of the hypolimnion (approximately $5^{\circ} \mathrm{C}$ ). Sediment cores were placed in an insulated container immediately after collection, and then transferred to a large refrigerator upon return to the field station. When this failed to prevent separation, we collected sediment cores in winter. Even when air temperatures were approximately $30^{\circ} \mathrm{C}$, separation of sediment cores occurred. In hindsight, these results are not surprising, given that the solubility of methane in water changes little with temperature (Yamamoto et al. 1976). Consequently, we hypothesized that the change in pressure must be responsible for the cores separating. The ambient pressure at the water surface is about half that at a depth of $10 \mathrm{~m}$ in a freshwater lake (Hutchinson 1957). This drastic reduction in pressure was likely what provoked dissolved gases to come out of solution, forming the bubbles that cleaved the cores. We decided the most feasible method of maintaining the sediment cores under ambient pressure conditions was to incubate the cores at the bottom of the lake. We designed a simple, inexpensive piece of equipment (hereafter referred to as the "Sediment Core Lander") that has allowed us to successfully conduct in situ sediment core incubation experiments in Lake 227, and other lakes.

\section{DESCRIPTION OF METHOD}

A detailed diagram of the Sediment Core Lander is provided in figure 1A. For our purposes, we designed a
Lander to hold fifteen $5.1 \mathrm{~cm}$ inner diameter, $60 \mathrm{~cm}$ high core tubes. The four shelves $(30 \times 50 \mathrm{~cm})$ and two wings $(30 \times 100 \mathrm{~cm})$ are made from $6 \mathrm{~mm}$ thick high-density polyethylene plastic. The top shelf has a locking trap door and two handles, the middle two shelves are identical, each having fifteen holes ( $6.4 \mathrm{~cm}$ diameter), and the bottom shelf has four holes to accept the bolts for the wing assembly. The four shelves are assembled with $3 / 8$ " threaded rods (each $70 \mathrm{~cm}$ long), with locking washers and standard hexagonal nuts above and below each shelf (with the exception of the top and bottom shelf, where locking nuts are placed at the ends of the rods). The wings are connected to one another with two aluminum corners (each $123 \mathrm{~cm}$ long) and attached to the bottom shelf with standard bolts and wing nuts (to allow disassembly during transport). Four ropes (each $53 \mathrm{~cm}$ long) are attached to the wings and joined together with a large carabineer; these ropes are threaded through PVC pipes (each $40 \mathrm{~cm}$ long) to prevent tangling and snagging. A $10 \mathrm{~m}$ long rope with a large float is also attached to the carabineer. In the field, the Sediment Core Lander is loaded with core tubes and slowly lowered, using the rope, to the bottom of the lake for the duration of the incubation (Fig. 1B). In lakes with highly flocculent sediments, it may be necessary to keep cores under pressure during sediment coring. In this case, the Sediment Core Lander should be attached to the boat and submersed to sufficient depth, then retrieved as each core is collected. 


\section{DISCUSSION}

The in situ sediment core incubation technique we describe in this paper has several advantages over laboratory-based incubations. First, this technique does not require transporting cores back to the laboratory, thereby minimizing the handling and disturbance of sediments that could otherwise confound the results of the incubation experiments. Second, this technique permits incubation of flocculent sediments which are prone to separation if not kept under ambient pressure. Third, the Sediment Core Lander is inexpensive to construct (approx. \$150 USD for materials), which is a small fraction of the cost of a temperature- and light-controlled growth chamber or anaerobic glove box (from $\$ 7000$ up to $\$ 25,000$ USD). Lastly, and most importantly, this technique exposes cores to natural ambient environmental conditions. Sediments incubated in situ experience natural temperature and light regimes, which are impossible to recreate exactly in the laboratory. Furthermore, submersion of the Sediment Core Lander into an anoxic hypolimnion ensures that anaerobic conditions are easily and effectively maintained in the sediment cores throughout the incubation. Because the Sediment Core Lander allows for the in situ incubation of sediments, we anticipate this approach will be useful for investigating a wide range of sediment processes in aquatic ecosystems.

\section{ACKNOWLEDGMENTS}

We thank Ray Pambrum, Paul Blanchfield, and Jeff Johnson for providing construction advice, Stephanie Sirman and Maily Huynh for assisting with field trials, and Jan Orihel and Magna-Tech Graphics for producing artwork. David W. Schindler provided a helpful critique of an early draft of this manuscript. DO is supported by the
University of Alberta, National Science and Engineering Council of Canada, Alberta Ingenuity Fund, and Friends of the Experimental Lakes Area.

\section{REFERENCES}

Burley KL, Prepas EE, and Chambers PA. 2001. Phosphorus release from sediments in hardwater eutrophic lakes: the effects of redox-sensitive and -insensitive chemical treatments. Freshwater Biol. 46: 1061-1074.

Campbell P. 1976. Descriptive limnology of Lake 120, a meromictic lake on the Precambrian Shield in northwestern Ontario [M. Sc. thesis]. Winnipeg: University of Manitoba: $122 \mathrm{pp}$.

Gilmour CC, and Riedel GS. 1995. Measurement of Hg methylation in sediments using high specific-activity $203 \mathrm{Hg}$ and ambient incubation. Water, Air, Soil Pollut. 80: 747-756.

Hutchinson G. 1957. A Treatise on Limnology. Volume I: Geography, Physics, and Chemistry. New York: John Wiley, and Sons, Inc.

Nowlin WH, Evarts JL, and Vanni MJ. 2005. Release rates and potential fates of nitrogen and phosphorus from sediments in a eutrophic reservoir. Freshwater Biol. 50: 301-322.

Schindler DW, Hecky RE, Findlay DL, Stainton MP, Parker BR, Paterson MJ, Beaty KG, Lyng M, and Kasian SEM. 2008. Eutrophication of lakes cannot be controlled by reducing nitrogen input: Results of a 37-year whole-ecosystem experiment. P. Natl. Acad. Sci. U.S.A. 105: 11254-11258.

Schindler DW, Hesslein RH, and Turner MA. 1987. Exchange of nutrients between sediments and water after 15 years of experimental eutrophication. Can. J. Fish. Aquat. Sci. 44: 26-33.

Schwarz JIK, Eckert W, and Conrad R. 2008. Response of the methanogenic microbial community of a profundal lake sediment (Lake Kinneret, Israel) to algal deposition. Limnol. Oceanogr. 53: 113-121.

Yamamoto S, Alcauskas JB, and Crozier TE. 1976. Solubility of methane in distilled water and seawater. J. Chem. Eng. Data 21: 78-80. 